\title{
Volunteer doctors start a clinic for the marginalized of New York city
}

The charity Doctors of the World was there to help injured and homeless people after hurricane Sandy hit, but after seeing a long standing need for health services in the area it has established a permanent base, writes Edward Davies. The charity is well versed in bringing care to the most vulnerable people all over the world, which is why the BMJ has chosen it for this year's Christmas appeal. Please give generously

\section{Edward Davies US news and features editor, BMJ}

New York, USA

When hurricane Sandy hit New York city in October 2012 it focused the health community's attention on the battered coastal area of the Rockaways. However, it didn't spark a major healthcare crisis-because one had existed for some time. This southern corner of the borough of Queens has only one hospital for its 130000 residents, with little access to an alternative, and had been designated an underdoctored area long before Sandy hit. About 27\% of its inhabitants are uninsured, and a similar number live below the poverty line.

Doctors of the World first arrived in the Rockaways a year ago in the immediate aftermath of a hurricane that destroyed thousands of homes. But it's now establishing a more permanent base, and just a few weeks ago opened the Rockaways Free Clinic as part of its mission to provide healthcare access to underserved and marginalized populations.

The clinic offers primary and preventive care regardless of ability to pay, and services include treatment for diabetes, hypertension, and other chronic diseases, along with mental health services and community health education. It's establishing a network of providers along with existing clinics, nurse visitors, and local charities, but they are up against huge need.

\section{Storm damage}

"This building used to be a clinic but it was washed out by the storm and the doctors simply never came back," says medical director Amber Featherstone.

"The next clinic is a federally qualified healthcare centre 40 blocks from here. Transport's not great, especially since the hurricane, and if you don't have a car that's a long way to walk, especially if you have a chronic condition."
Many of the patients she sees are unemployed and uninsured, both long term and as a direct result of the hurricane: "I saw a patient last week who lost his job after the local chocolate factory was hit and has never found another one." The Madelaine Chocolate Factory was one of the biggest employers in the Rockaways and only recently managed to rehire a third of its former 450 workers, a year after the hurricane closed it down. ${ }^{1}$

She describes another patient whose seizures, she believes, were triggered by the stress of dealing with the aftermath of the hurricane, but also countless people with chronic conditions such as asthma and diabetes whose problems predate the hurricane but were never dealt with properly.

And with such high unemployment in the area, the need for a free point of care is enormous.

"We have patients who were unemployed, uninsured, and struggling to pay for medication so would buy medication but not go to a doctor because they couldn't afford both. We can see those patients now and provide medication for the first month as well.

"We'd like to see patients with chronic conditions afford their medication beyond the first month."

The clinic is currently funded entirely by donations from private individuals and corporations and relies on volunteer doctors to staff its sessions.

At $\$ 201$ (£127; €150) a visit on average, it is not cheap to run, but that includes all medications, tests, and services and ensures that no part of anybody's treatment in any way depends on their ability to pay. 


\section{What is the charity doing in NYC?}

So what is an organisation like Doctors of the World, better known for working in conflict and crisis zones, doing in one of the richest cities on earth? The answer is simple, says programme coordinator Noah Barth: "Doctors of the World is about serving vulnerable populations and they can be found anywhere unfortunately. We view healthcare as a fundamental human right and we are all still humans.

"We also bear witness for the conditions of our clients and advocate for their plight. People paid attention to the Rockaways because of the hurricane, but there was a severe shortage of health providers long before."

However, the work of Doctors of the World does extend far beyond New York City. It currently runs over 300 programmes in over 70 countries. It has recently sent emergency workers to help the survivors of typhoon Haiyan in the Philippines, ${ }^{2}$ is providing care for Syrian refugees in Jordan and Lebanon, ${ }^{3}$ and is working to lower maternal and infant mortality rates in the Sindhulpalchok district of Nepal, where only $5 \%$ of births take place with medical care available. All of its work relies on donations from individuals of both time and money.

Competing interests: I have read and understood the BMJ Group policy on declaration of interests and have no relevant interests to declare.

Provenance and peer review: Not commissioned; not externally peer reviewed.

1 Colangelo LL. Chocoholics rejoice! Madelaine's is up and running in Rockaway. $N$ Y Daily News 2013 Oct 22. www.nydailynews.com/new-york/queens/chocolate-factory-churnsold-days-article-1.1493149.

2 Feinmann J. After the typhoon: how volunteer doctors are bringing medical care to those most in need. BMJ 2013;347:f7193

3 Hurley R. Who cares for the nine million displaced people of Syria? BMJ 2013;347:f7374.

Cite this as: BMJ 2013;347:f7586

๑ BMJ Publishing Group Ltd 2013 


\section{Please give generously to Doctors of the World}

To donate go to www.doctorsoftheworld. org.uk/BMJ or phone \pm 44 (0)20 35357955 . To donate $£ 10$ by text message text DOCTOR to 70030 (UK mobiles only). 